Original Research

\title{
Examining Economic Development and Carbon Emissions in China's Low-Carbon Pilot Provinces
}

\author{
Chen Li ${ }^{1}$, Xiaohu Li', Xigang Zhu' ${ }^{2 *}$ \\ ${ }^{1}$ School of Geographic and Oceanographic Sciences, Nanjing University, Nanjing, Jiangsu 210023, China \\ ${ }^{2}$ School of Architecture and Urban Planning, Nanjing University, Nanjing, Jiangsu 210093, China
}

Received: 30 October 2016

Accepted: 16 April 2017

\begin{abstract}
Taking small-scale areas as research units, this paper empirically explores the dynamic relationship between economic development and carbon emissions from 1995 to 2013 in China's low-carbon pilot provinces. This subject has been neglected in the literature. We first apply decoupling theory to analyse the decoupling of economic development and carbon emissions. We then apply a STIRPAT model and ridge regression to deconstruct the mechanism whereby economic development influences carbon emissions in China's low-carbon provinces. Empirical results show a positive linear correlation between economic development and carbon emissions in the examined provinces. We find that population size and industrial structure most prominently affect carbon emissions; however, per capita wealth, technological progress, and policy factors do not show the expected significance. Our results allow policymakers to formulate lowcarbon policies on the basis of empirically verified situations in the examined regions. They suggest that restricting population growth and transforming industrial structures are the keys to reducing China's carbon emissions.
\end{abstract}

Keywords: low-carbon pilot provinces, economic development, carbon emissions, tapio decoupling model, STIRPAT model, ridge regression

\section{Introduction}

Global warming imperils human survival and development, and carbon emissions from human activities are the main cause of global warming [1]. As the world's largest developing country and a fast-growing economy, China leads the globe in carbon emissions, and its government has promised to cut carbon emission intensity to $40 \%$ to

*e-mail: zhuxigang227@163.com
$45 \%$ of 2005 levels by 2020 . Toward this end, it formulated a low-carbon development plan in which low-carbon pilot projects are a key element. Without constraints provided by specialised policy, local governments might ignore the carbon emissions issues to pursue economic growth. Considering this, low-carbon pilot projects are important tools to reduce carbon emissions attendant to economic development.

Numerous studies relate economic development and carbon emissions through the mechanism of the Environmental Kuznets Curve (EKC) [2]. Applying variant approaches, Halicioglu [3], Puliafito et al. [4], Al-mulali 
et al. [5], and Yavuz [6] uncovered an inverted U-shaped relationship between economic development and carbon discharge. Lau et al. [7] observed the EKC for Malaysia as did Shahbaz et al. [8] for Tunisia. However, Galeotti et al. [9], Yang et al. [10], and Jayanthakumaran et al. [11] found no evidence for the EKC in some countries. Their findings are consistent with Fodha and Zaghdoud [12] and Haghnejad and Dehnavi [13]. In short, there is controversy concerning the existence of the EKC. Furthermore, Wang et al. [14] noted a linear relationship in panel data for China between economic development and carbon discharges. Similar conditions appear in Tunisia [12] and Turkey [15].

Scholars have sought to discern causal relationsships between economic development and carbon discharges via the granger causality and cointegration tests. Wu et al. [16] found only a one-way positive correlation from carbon emissions to economic growth in China. Using Chinese provincial data spanning 1995-2009, Du et al. [17] found that economic development is a key factor impacting carbon emissions. Feng et al. [18] found that rising affluence significantly contributes to carbon emissions. In their study of Beijing, Wang et al. [19] noted that economic development, urbanisation, and industrial structure positively influence carbon emissions, with urbanisation being the most influencing factor. Wang et al. [20] found that per capita GDP, urbanisation, population, service level, and industrialisation may increase carbon emissions. Overall, most results show that economic development causes carbon emissions but does not always follow from increases in emissions. Cointegration tests demonstrate a more stable co-integration relationship between economic development and carbon emissions.

The IPAT model is most commonly used to assess the effects of economic development on carbon emissions. It regards environmental impact $(I)$ as the product of population $(P)$, affluence $(A)$, and technology $(T)$. The stochastic impacts by regression on population, affluence and technology model (STIRPAT) is derived from the IPAT model. Employing the STIRPAT model, Wang et al. [20] found that GDP growth can increase emissions in China's Guangdong Province, with population exerting the most significant effect. On the basis of these Chinese provincial data spanning 1995-2010, Zhang and Lin [21] used STIRPAT to show how urbanisation affects carbon emissions and found that economic growth drives emissions. Acaravci and Ozturk [22] reached similar conclusions for some European countries, as did Rafindad [23] for Nigeria, and Shahbaz et al. [24] and Alkhathlan and Javid [25] for Saudi Arabia. Furthermore, numerous scholars have analysed how population, per capita wealth, technological progress, industrial structure, international trade, and urbanisation affect carbon emissions [26-30]. Most studies show that carbon emissions relate closely to economic growth, industrial structure, technological progress, and consumption patterns [19, 31-32]. The effects of industrial structure are especially prominent [33-34].
In addition, many researchers have developed simulations to predict changes in carbon emissions through economic growth. Liang et al. [35] adopted an input-output model to perform scenario analysis for China's carbon emissions in 2020. Using a dynamic computable general equilibrium model, Jiang and Du [36] defined three scenarios to forecast China's energy demand in 2030 and predicted that China will confront serious carbon emissions. Golley and Meng [37] demonstrated that high income levels engender more carbon emissions. Most national results show that carbon emissions differ in urban and rural areas, with cities as their main source [38-39].

The impact of environmental regulations on carbon emissions has attracted extensive attention. Applying Chinese company data for 2007-12, Zhao and Sun [40] found that environmental regulations encourage pollutionreducing innovation. Furthermore, Huang and Gao [41] found that environmental regulation is conducive to reducing carbon emissions among Chinese provinces. Employing panel data covering 2000-11 for Chinese provinces, Zhang and Wei [42] uncovered an inverted U-shaped relationship between environmental regulations and carbon emissions, a conclusion confirmed by Huang and Gao [43]. However, Zhang et al. [44] determined that environmental regulations did not promote emissionsreducing technological innovation in China. In summary, regulations present merits and defects [45-47], and environmental regulations are no exception.

Unfortunately, these previous studies have limitations. First, they concentrate on macro regions and overlook smaller areas. Extensive literature investigates major countries, regional organisations (EU, BRIC countries, East Asia) and individual countries (China, the United States, India), but few studies have examined interior areas within a country even though economic ties to carbon emissions have strong regional characteristics. This inevitably means that conclusions and policy recommendations are not targeted and actionable.

Second, previous studies seldom investigate areas that have implemented policies to reduce carbon emissions. They note the influence of factors affecting regional carbon emissions but do not inspect policy effects in areas that have implemented carbon discharge policies.

Third, previous studies mainly seek to predict global or regional carbon emissions but ignore the chronological dynamics of economic development and carbon emissions. They fail to capture the mechanisms by which economic development and carbon emissions evolve.

This study address these limitations of previous research. It studies China's latest low-carbon pilot provinces as test cases in developing a low-carbon economy. It analyses the mechanisms through which economic development affects carbon emissions. In doing so, it assesses China's environmental progress, identifies problems in curtailing carbon emissions, and establishes an empirical reference for the promotion of low-carbon economies throughout China. 
Our study makes four contributions to the literature. First, it is the ground-level investigation of China's lowcarbon pilot provinces. Previous studies ignore the effects of specialised policies on microscale areas. Second, it is singular in applying the decoupling theory to inspect economic development and carbon emissions in districts that established low-carbon polices. Moreover, we incorporated policy factors into the STIRPAT model, expanding it to assess the impact of policy on emissions. Third, it identifies mechanisms through which economic development and carbon emissions evolve in areas that have implemented carbon reduction polices. Fourth, we situate low-carbon pilot projects in the context of environmental regulation and evaluate the effects of lowcarbon policies. Although numerous studies examine China's carbon emissions, few track the effects of carbon reduction under the constraints of policies governing pilot projects. Therefore, our findings provide a valuable and operable policy reference for promoting low-carbon pilots in China and elsewhere.

This paper is structured as follows. Section 2 explains material and methods. Section 3 presents the results and the discussion. Section 4 concludes and recommends policies.

\section{Material and Methods}

\section{Case Study}

To achieve carbon reduction targets, China's government established low-carbon pilot projects in selected provinces in 2010. Provinces most recently designated (Fig. 1) include Guangdong, Liaoning, and Hainan on the eastern coast, the central region of Hubei province, and the western interior of Shaanxi and Yunnan provinces. According to official documents, low-carbon pilot provinces were determined on the basis of low-carbon development and geographical situation. There are both the eastern developed provinces and inland underdeveloped provinces. All pilot provinces have established peak emissions targets generally to be achieved by 2025 or before. Each province was tasked with proposing mediumand long-term carbon intensity reduction goals (Fig. 1).

Moreover, the overall initiative requires designated provinces to reduce carbon emissions to targets specified in the regional Twelfth Five-Year Plan. It requires them to plan for low-carbon development, combining industrial restructuring, optimising resource use, saving energy, reducing emissions, and increasing carbon sinks. It calls for establishing a carbon emission constraint index with identified tasks and concrete measures to cut carbon emission intensity and explore a low-carbon development model. Therefore, the initiative opens a window for observing the relationship between economic development and carbon emissions.

Table 1 lists socioeconomic indicators of the lowcarbon pilot provinces. The population in Guangdong is approximately 11 times that of Hainan. Urbanisation ranges from $38.91 \%$ in Yunnan to $77.80 \%$ in Liaoning, and per capita GDP of Guangdong is almost thrice that of Yunnan. Secondary industries contribute only $25 \%$ of Hainan's GDP versus nearly $50 \%$ in Guangdong. The service sector remains relatively undeveloped, producing $43 \%$ of GDP in Hainan and 36\% in Hubei and Yunnan. Economic growth exceeds $10 \%$ in all provinces except

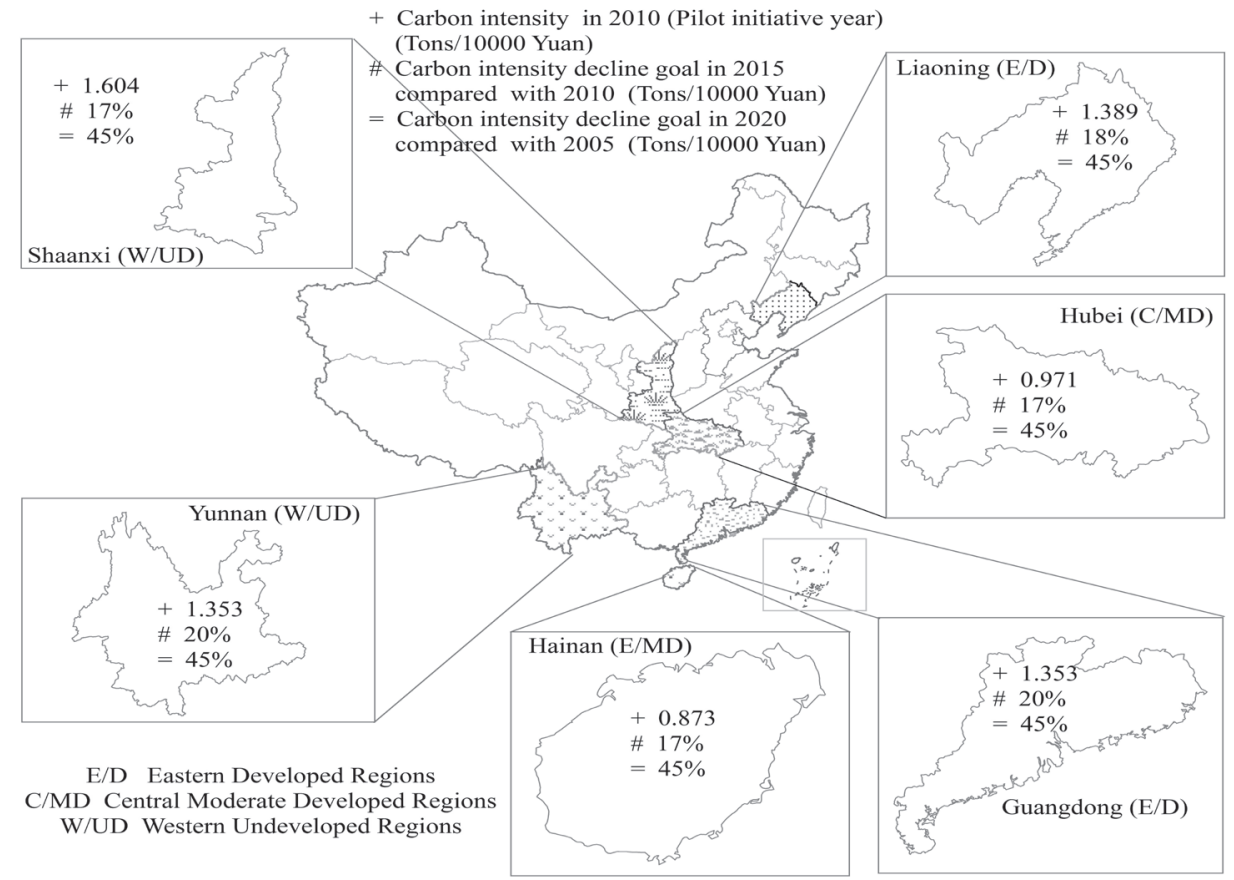

Fig. 1. Locations and major goals of China's low-carbon pilot provinces. 
Table 1. Socioeconomic indicators of China's low-carbon pilot provinces.

\begin{tabular}{|c|c|c|c|c|c|c|}
\hline Index type & Guangdong & Liaoning & Hubei & Shaanxi & Yunnan & Hainan \\
\hline Population (10 ${ }^{4}$ people) & $8,952.36$ & $4,245.53$ & $5,751.10$ & $3,667.91$ & $4,381.79$ & 815.13 \\
\hline Per capita GDP (yuan) & $21,897.00$ & $19,020.49$ & $12,381.94$ & $8,834.49$ & $7,075.17$ & $11,621.89$ \\
\hline Proportion of three industries (\%)* & $3: 56: 41$ & $7: 55: 38$ & $21: 43: 36$ & $12: 51: 37$ & $18: 46: 36$ & $32: 25: 43$ \\
\hline Urbanisation level (\%) & 66.46 & 77.80 & 56.44 & 51.61 & 38.91 & 49.43 \\
\hline GDP growth rate (\%) & 11.84 & 10.78 & 11.44 & 12.18 & 10.47 & 9.86 \\
\hline
\end{tabular}

Note: Data are averages for each pilot province during 1995-2013. The * indicates that the three industries are primary, secondary, and tertiary.

Hainan. Socioeconomic indicators reveal that pilot provinces differ in stages of development.

\section{Estimating Carbon Emissions}

China does not disclose carbon emissions data, so emissions can only be estimated by other methods. China's carbon emissions originate mainly from the consumption of fossil energy, so fossil energy consumption can be used to represent carbon emissions. Considering the availability and calibre of data, we estimate carbon emissions in pilot provinces from the consumption of coal, coke, oil, fuel oil, gasoline, kerosene, diesel oil, and natural gas. Since data from the China Energy Statistical Yearbook are presented as physical volume, we converted the data into quantities of consumed coal using standard coefficients. We estimated carbon emissions using Eq. (1):

$$
C=\sum_{i}\left(E_{i} \times F_{i}\right)
$$

.... where $C$ denotes carbon emissions, $i$ the type of energy, $E_{i}$ denotes consumption standards from $i$, and $F_{i}$ (the carbon emission coefficient of $I$ ) is from the Intergovernmen-

Table 2. Conversion coefficients and carbon emission coefficients of standard coal from different energy sources.

\begin{tabular}{|c|c|c|}
\hline $\begin{array}{c}\text { Types of } \\
\text { energy }\end{array}$ & $\begin{array}{c}\text { Converted coefficient } \\
\text { of energy by standard } \\
\text { coal }(\mathrm{kg} / \mathrm{kg})\end{array}$ & $\begin{array}{c}\text { Carbon emission } \\
\text { coefficient } \\
\text { of energy }(\mathrm{kg} / \mathrm{kg})\end{array}$ \\
\hline Coal & 0.7143 & 0.7559 \\
\hline Coke & 0.9714 & 0.8550 \\
\hline Oil & 1.4286 & 0.5857 \\
\hline Fuel oil & 1.4286 & 0.6185 \\
\hline Gasoline & 1.4714 & 0.5538 \\
\hline Kerosene & 1.4714 & 0.5714 \\
\hline Diesel oil & 1.4571 & 0.5921 \\
\hline Natural gas & 1.2722 & 0.4483 \\
\hline
\end{tabular}

Note: Data are from General Principles for Calculation of Comprehensive Energy Consumption, 2008. tal Panel on Climate Change's (IPCC) default values for carbon emission estimates (Table 2).

\section{Tapio Decoupling Model}

The decoupling theory proposed by the Organization for Economic Co-operation and Development (OECD) includes two indicators of decoupling factors and a decoupling index to analyse relationships between economic development and carbon emissions. The index is partitioned into strong decoupling, weak decoupling, weak negative decoupling, strong negative decoupling, expansionary negative decoupling, expansion of the connection, and recessive decoupling and connection to degradation.

Strong decoupling refers to economic growth and carbon emissions decline - i.e., the decoupling index is less than 0 . Weak decoupling refers to increases in economic activity and carbon emissions, but growth in carbon emissions is below economic growth - i.e., the decoupling index is between 0 and 0.8 . Weak negative decoupling refers to declines in economic activity and carbon emissions, but carbon emissions declined less than economic slowdown - i.e., the decoupling index is between 0 and 0.8 . Strong negative decoupling refers to periods in which economic growth declined, but carbon emissions rose - i.e., the decoupling index is less than 0 . The expansion of connection indicates that economic activity and carbon emissions rose geometrically - i.e., the decoupling index is between 0.8 and 1.2. Expansionary negative decoupling refers to carbon emissions growth that exceeds economic growth. In this case, the decoupling index exceeds 1.2. Recession connection refers to economic recession and carbon emissions during periods of negative growth, and the decoupling index is between 0.8 and 1.2. Recession decoupling refers to declines in economic activity and carbon emissions, but the decline in carbon emissions exceeds the decline in economic growth - i.e., the decoupling index exceeds 1.2.

China's economic growth was rapid during our study period, so there was no likelihood of strong negative decoupling, weak negative decoupling, recessive decoupling, or connection to degradation. According to the principles of decoupling theory and characteristics of the decoupling index, the decoupling index formula is expressed as follows: 


$$
\begin{aligned}
& C_{t}=\left(\frac{C_{t 1}-C_{t 0}}{C_{t 0}}\right) /\left(\frac{E_{1}-E_{0}}{E_{0}}\right) \\
& C_{p}=\left(\frac{C_{p 1}-C_{p 0}}{C_{p 0}}\right) /\left(\frac{E_{1}-E_{0}}{E_{0}}\right) \\
& C_{i}=\left(\frac{C_{i 1}-C_{i 0}}{C_{i 0}}\right) /\left(\frac{E_{1}-E_{0}}{E_{0}}\right)
\end{aligned}
$$

...where $C_{t}, C_{p}$, and $C_{i}$ represent the decoupling index of carbon emissions, per capita carbon emissions, and carbon emission intensity, respectively. $C_{t 0}$ and $C_{t 1}$ represent the starting and ending years of carbon emissions. $E_{0}$ and $E_{l}$ refer to GDP in the starting year and ending year, respectively. $C_{p 0}$ and $C_{P 1}$ indicate per capita carbon emissions in the starting and ending years, respectively. $C_{i 0}$ and $C_{i l}$ indicate carbon emission intensity in the starting and ending years, respectively.

\section{STIRPAT Model}

The stochastic impacts by regression on population using the IPF model, where $I$ stands for environmental impact, $P$ stands for population size, and $F$ stands for pressure of the population on the environment, reflects the relationship between population and the environment [48]. With per capita wealth and technological progress joined, IPF evolved into the IPAT model, where the means of $I$ and $P$ are those in the IPF model and $A$ and $T$ denote per capita wealth and technological progress [49-50]. However, the IPAT model takes environmental pressure and its influences as a geometric linear relationship. It does not capture influences from factors affecting the degree of impact on the environment. Therefore, Dietz and Rose proposed the STIRPAT model. Its mathematical expression is:

$$
I=a P^{b} A^{c} T^{d} e
$$

...where $I$ is environmental influences represented by carbon emissions; $a$ is the coefficient for population size; and $b, c$, and $d$ stand for corresponding independent variable indexes, respectively. $e$ is the error term. When $a=b=c=d=1$, STIRPAT is the IPAT model. The STIRPAT model can be transformed into a multiple linear regression equation in logarithmic form:

$$
\ln I=\ln a+b \ln P+c \ln A+d \ln T+\ln e
$$

The STIRPAT model can be expanded by adding a parameter such as urbanisation to investigate its impact on environmental pressure or a parameter capturing the square of wealth to verify the Environment Kuznets Curve.
We add the urbanisation rate $(U)$, industrial structure $(C Y)$, and wealth of a second party as independent variables into the STIRPAT model. To investigate the effects of China's low-carbon policy, we add the policy variable $(Z C)$. Thus, the model is extended to the following:

$$
\begin{gathered}
\ln I=\ln a+b_{1} \ln P+b_{2} \ln U+c_{1} \ln A+c_{2}(\ln A)^{2} \\
+d_{1} \ln T+d_{2} \ln C Y+f \ln Z C+\ln e
\end{gathered}
$$

By making partial derivative of the first order to $\ln A$ in Eq. (7), we obtain the effects of the elasticity of the coefficient of per capita wealth on carbon emissions. We use this to measure the pressure on the environment caused by rising per capita wealth. The influence of economic development on the environment is further obtained by the following:

$$
E_{i}=C_{1}+2 C_{2} \ln A
$$

...where $E_{i}$ stands for environmental impact; $C_{1}$ and $\mathrm{C}_{2}$ are estimated coefficients of per capita wealth and its quadratic, respectively; and $A$ is per capita wealth.

\section{Data Source and Variable Explained}

Our data mainly come from the China Energy Statistical Yearbook and the China Statistical Yearbook from 1996 to 2014. We adjusted the base period of the economic data to 1995 to eliminate price fluctuations. The dependent variable is carbon emissions $(10,000$ tons). Independent variables include population size, urbanisation rate, per capita wealth, technological progress, industrial structure, and policy factors. Among them, population size $(10,000)$ is provincial population at year-end. Urbanisation rate accounts for the proportion of urban population in the total population. Wealth is represented as per capita GDP $(10,000$ yuan). Technical progress is denoted by energy intensity. The industrial structure is denoted by the share of secondary industry. The policy is shown in the use of the dummy variable. We set the policy at 0 before the pilot of the low-carbon policy is implemented and then set the policy at 1 after the pilot of the low-carbon policy is implemented.

Table 3 is a descriptive analysis of variables. The mean value for population is 46.36 million, with a coefficient of variation of 0.54 . The high (minimum) value for urbanisation is $67.76 \%(13.64 \%)$. The highest value for industrial structure is thrice the lowest. Average per capita GDP is $13,471.83$ yuan, the coefficient of variation is 0.71 , and the maximum value is more than 15 times the minimum. The disparity in energy intensity is significant, with the maximum value being more than nine times the minimum. 
Table 3. Descriptive analysis

\begin{tabular}{|c|c|c|c|c|c|}
\hline Variable & Mean & Min & Max & CV & Expected impact* \\
\hline Population (10 people) $^{4}$ & $4,635.64$ & 724.00 & $10,644.00$ & 0.54 & Positive \\
\hline Urbanisation (\%) & 42.45 & 13.64 & 67.76 & 0.33 & Positive or negative \\
\hline Industrial structure (\%) & 46.02 & 20.55 & 64.01 & 0.25 & Positive \\
\hline Per capita GDP (yuan) & $13,471.83$ & $2,843.00$ & $43,439.90$ & 0.71 & Positive or negative \\
\hline Energy intensity (tons/10 ${ }^{4}$ yuan) & 1.78 & 0.54 & 4.43 & 0.47 & Positive \\
\hline Policy (dummy variable) & 0.19 & 0.00 & 1.00 & 2.05 & Positive \\
\hline
\end{tabular}

Note: $\mathrm{CV}$ indicates coefficient of variation. * indicates the expected impact reference to previous research.

\section{Results and Discussion}

\section{Trend in Carbon Emissions and Intensity}

Applying Eq. (1) and the carbon emission coefficient from Table 1, we estimated carbon emissions and obtained the carbon emission intensity in the low-carbon pilot provinces during 1985-2013. The results are provided in Fig. 2.

a)

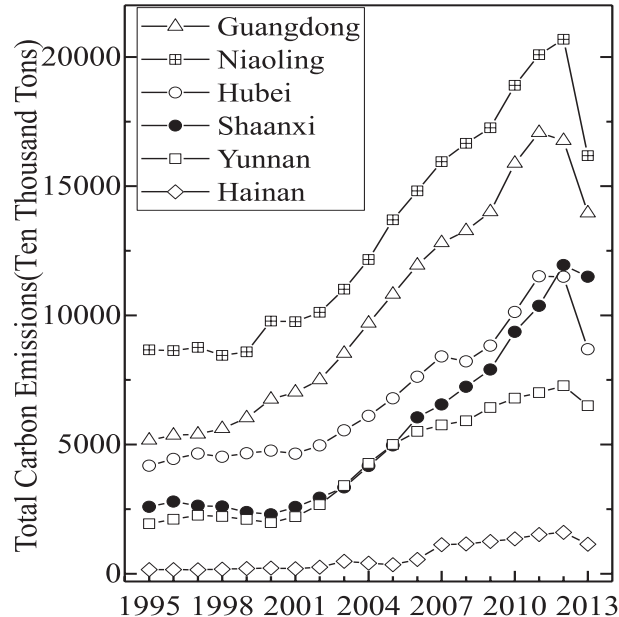

b)

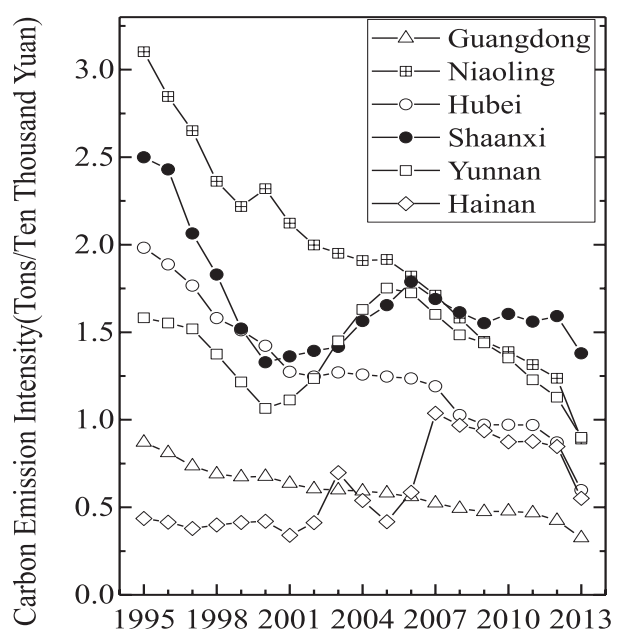

Fig. 2. Carbon emissions a) and carbon emission intensity b) in China's low-carbon pilot provinces.
As Fig. 2a) shows, carbon emissions in China's lowcarbon pilot provinces rose rapidly during 1995-2012. Located in heavily industrialised northeastern China, Liaoning Province emitted the most carbon, followed by coastal Guangdong Province. Its advanced economy consumes copious amounts of energy. Tourism drives the economy of less industrialised Hainan, and it emitted the least number of carbons during the period. Carbon emissions in Yunnan, Shaanxi, and Hubei are notable. These provinces in midwestern China are industrialising and urbanising rapidly, although carbon emissions in Yunnan slowed after 2006. Overall, carbon emissions in all provinces accelerated significantly during 2000-11 and declined consistently after 2012 .

Fig. 2b) depicts carbon intensity in the pilot provinces. Liaoning displays the greatest carbon intensity during 19952007 but declines rapidly. Shaanxi overtook Liaoning early in 2008. Shaanxi is adjacent to Shanxi Province, where coal is produced. Coal commands a higher proportion of energy consumption, so its carbon intensity is larger, likely because it was in the midst of industrialisation during the period. Hainan's carbon intensity is less but displays a pattern of decrease-increase-decrease with large fluctuations. Guangdong's carbon intensity declines steadily in Fig. 2b, falling from 0.87 tons/CNY 10,000 in 1995 to 0.33 in 2013. Guangdong, one of China's most economically developed provinces, has progressed significantly toward a low-carbon economy. The carbon intensity of Central Hubei is declining continuously. Western Yunnan presents a pattern of decline-increasedecline. Low-carbon economic development took many twists and rebounded during 2001-05. Carbon intensity of all provinces declined rapidly after 2012, illustrating the success of low-carbon policies.

\section{Decoupling Analysis of Carbon Emissions and Economic Development}

We divided the study period into 1995-2001, 200107, and 2007-13 and used Eqs (2-4) to calculate an index for the decoupling of per capita carbon emissions and carbon intensity during 1995-2013 in the low-carbon pilot provinces. Table 4 illustrates the decoupling by type of economic development and carbon emissions: 
Table 4. Trend in decoupling of carbon emissions and GDP in China's low-carbon pilot provinces (1995-2013).

\begin{tabular}{|c|c|c|c|c|c|c|c|c|c|c|c|}
\hline Region & Time (year) & $\begin{array}{c}\left(E_{l}-\mathrm{E}_{0}\right) / \\
E_{0}\end{array}$ & $\begin{array}{c}\left(C_{t 1}-\mathrm{C}_{t 0}\right)^{\prime} \\
C_{t 0} \\
\end{array}$ & $G_{t}$ & $\begin{array}{c}G_{t} \\
\text { Type }\end{array}$ & $\begin{array}{c}\left(C_{P I}-C_{P 0}\right)^{\prime} \\
C_{P 0}\end{array}$ & $C_{p}$ & $\begin{array}{c}C_{p} \\
\text { Type }\end{array}$ & $\begin{array}{c}\left(C_{i 1}-C_{i 0}\right) / \\
C_{i 0}\end{array}$ & $C_{i}$ & $\begin{array}{c}C_{i} \\
\text { Type }\end{array}$ \\
\hline \multirow{3}{*}{ Guangdong } & 1995-2001 & 0.86022 & 0.35960 & 0.41803 & $\nabla$ & 0.06922 & 0.08047 & $\nabla$ & -0.26912 & -0.31285 & $\Delta$ \\
\hline & 2001-07 & 1.21585 & 0.82300 & 0.67690 & $\nabla$ & 0.64818 & 0.53311 & $\nabla$ & -0.17729 & -0.14582 & $\Delta$ \\
\hline & $2007-13$ & 0.75311 & 0.08948 & 0.11882 & $\nabla$ & -0.01128 & -0.01498 & $\Delta$ & -0.37854 & -0.50264 & $\Delta$ \\
\hline \multirow{3}{*}{ Liaoning } & 1995-2001 & 0.64501 & 0.12568 & 0.19486 & $\nabla$ & 0.09831 & 0.15241 & $\nabla$ & -0.31570 & -0.48945 & $\Delta$ \\
\hline & 2001-07 & 1.02812 & 0.63508 & 0.61772 & $\nabla$ & 0.59552 & 0.57923 & $\nabla$ & -0.19379 & -0.18849 & $\Delta$ \\
\hline & $2007-13$ & 0.95087 & 0.01428 & 0.01502 & $\boldsymbol{\nabla}$ & -0.00697 & -0.00733 & $\Delta$ & -0.48009 & -0.50489 & $\Delta$ \\
\hline \multirow{3}{*}{ Hubei } & 1995-2001 & 0.72902 & 0.11069 & 0.15183 & $\nabla$ & 0.13307 & 0.18253 & $\nabla$ & -0.35762 & -0.49055 & $\Delta$ \\
\hline & 2001-07 & 0.93549 & 0.81035 & 0.86623 & $\bullet$ & 0.79733 & 0.85231 & $\bullet$ & -0.06466 & -0.06911 & $\Delta$ \\
\hline & $2007-13$ & 1.06051 & 0.03343 & 0.03152 & $\boldsymbol{\nabla}$ & 0.01561 & 0.01472 & $\nabla$ & -0.49846 & -0.47002 & $\Delta$ \\
\hline \multirow{3}{*}{ Shaanxi } & 1995-2001 & 0.83185 & -0.00210 & -0.00253 & $\boldsymbol{\Delta}$ & -0.04011 & -0.04822 & $\Delta$ & -0.45525 & -0.54728 & $\Delta$ \\
\hline & 2001-07 & 1.04118 & 1.53292 & 1.47229 & घ & 1.49545 & 1.43630 & घ & 0.24091 & 0.23138 & $\boldsymbol{\nabla}$ \\
\hline & $2007-13$ & 1.14813 & 0.75447 & 0.65713 & $\nabla$ & 0.72837 & 0.63439 & $\nabla$ & -0.18326 & -0.15962 & $\boldsymbol{\Delta}$ \\
\hline \multirow{3}{*}{ Yunnan } & $1995-2001$ & 0.62303 & 0.14157 & 0.22722 & $\boldsymbol{\nabla}$ & 0.06238 & 0.10012 & $\nabla$ & -0.29664 & -0.47613 & $\boldsymbol{\Delta}$ \\
\hline & 2001-07 & 0.81117 & 1.60669 & 1.98071 & - & 1.47584 & 1.81939 & - & 0.43923 & 0.54148 & $\nabla$ \\
\hline & $2007-13$ & 1.01258 & 0.12973 & 0.12812 & $\nabla$ & 0.08812 & 0.08703 & $\nabla$ & -0.43867 & -0.43322 & $\Delta$ \\
\hline \multirow{3}{*}{ Hainan } & 1995-2001 & 0.56541 & 0.22218 & 0.39295 & $\nabla$ & 0.11226 & 0.19855 & $\nabla$ & -0.21926 & -0.38779 & $\Delta$ \\
\hline & 2001-07 & 0.90981 & 4.82386 & 5.30207 & - & 4.48285 & 4.92725 & - & 2.04945 & 2.25262 & - \\
\hline & $2007-13$ & 0.91053 & 0.01492 & 0.01639 & $\nabla$ & -0.04204 & -0.04617 & $\Delta$ & -0.46877 & -0.51484 & $\Delta$ \\
\hline
\end{tabular}

Note: $\boldsymbol{\nabla}$ indicates weak decoupling, $\boldsymbol{\Delta}$ indicates strong decoupling, $\bullet$ indicates an expansion connection, $\boldsymbol{\bullet}$ indicates expansionary negative decoupling.

As Table 4 shows, carbon emissions in all pilot provinces grew less than economic growth during 19952001. Most provinces exhibit weak decoupling of carbon emissions and economic growth. Only Shaanxi exhibits strong decoupling. The eastern coast of Hainan and Guangdong provinces stand higher in our decoupling index, and central Hubei and western Shaanxi rank relatively lower. Economic development increased carbon emissions mainly in the southeastern provinces. Only Shaanxi exhibits a negative relationship between economic development and carbon emissions. All pilot provinces rank relatively low in per capita growth of carbon emissions. The decoupling index is low and generally indicates weak decoupling, although Shaanxi exhibits strong decoupling. Economic development and per capita carbon emissions were more harmonious during the period. All pilot provinces display negative growth in carbon intensity. Carbon intensity per unit of GDP decreased, and economic quality improved steadily.

Over 2001 to 2007, growth in carbon emissions accelerated, outstripping economic growth in the pilot provinces. Our decoupling index reveals weak decoupling only in Guangdong and Liaoning. This period coincided with the Great West Development Strategy in China. Growth in carbon emissions among the western provinces exceeded economic growth, and the decoupling index rises significantly from 1995 to 2001. Hainan, Yunnan, and Shaanxi reveal expansive negative decoupling. This period overall reveals high economic growth and high emissions growth except in Liaoning and Guangdong, where economic development turned the environmental situation grim.

The index demonstrates weak decoupling for per capita carbon emissions except in economically developed Guangdong and Liaoning. Less-developed Shaanxi, Yunnan, and Hainan display expansionary negative decoupling as a result of uncoordinated economic and environmental development.

Carbon intensity declines only in Guangdong, Liaoning, and Hubei. It is positive for all other provinces, indicating inefficient economic development.

During 2007-13, the growth in carbon emissions slowed in all pilot provinces and was dramatic in Liaoning, Hainan, and Hubei. The decoupling index also declined. All provinces exhibit weak decoupling during the period, and carbon emissions were controlled effectively. Environmental damage from economic activity diminished. Per capita carbon emissions declined from the previous period in all provinces. Strong decoupling is evident for Guangdong, Liaoning, and Hainan, and weak decoupling is evident for all other provinces. 
Table 5. VIF values of independent variables for pilot provinces.

\begin{tabular}{|c|c|c|c|c|c|c|}
\hline Variable & Guangdong & Liaoning & Hubei & Shaanxi & Yunnan & Hainan \\
\hline $\ln A$ & $4,658.10$ & 567.58 & 444.50 & $1,143.93$ & $1,222.11$ & $5,391.52$ \\
\hline$(\ln A)^{2}$ & $2,119.17$ & 380.45 & 272.66 & 426.05 & 506.09 & $2,318.54$ \\
\hline $\ln P$ & 297.19 & 330.61 & 148.52 & 380.23 & 132.70 & 835.62 \\
\hline $\ln C Y$ & 250.62 & 267.71 & 54.98 & 191.10 & 63.42 & 103.81 \\
\hline $\ln U$ & 151.26 & 262.39 & 19.83 & 26.68 & 53.13 & 83.27 \\
\hline $\ln T$ & 62.54 & 29.05 & 13.14 & 17.08 & 5.64 & 6.71 \\
\hline $\ln Z C$ & 6.13 & 13.05 & 7.78 & 6.11 & 2.37 & 6.01 \\
\hline Mean $V I F$ & $1,077.86$ & 264.41 & 137.35 & 313.03 & 283.64 & $1,249.35$ \\
\hline
\end{tabular}

Growth in the intensity of carbon emissions fell in all pilot provinces. The decoupling index stands below 0 for the period - evidence of strong decoupling. During 20072013, China implemented its transition to a low-carbon economy. Industries that were high carbon emitters were restricted, and the transformation from extensive to intensive economic development progressed.

\section{Regression Analysis of the Impact of Economic Development on Carbon Emissions}

To investigate how economic factors influence carbon emissions, we employed multiple linear regression. As per the extended STIRPAT model in Eq. (7), we selected carbon emissions as the dependent variable and population size, per capita wealth, technological progress, urbanisation, industrial structure, and policy effects as independent variables. To test for the presence of the Environmental Kuznets Curve, we added the squared value of wealth as an independent variable. Because multiple regression requires independent variables, we first used least squares to fit Eq. (7). We then tested for correlation among independent variables. The results are shown in Table 5. It is evident that the maximum value of the variance inflation factor exceeds 10 and that the average value exceeds 1 . A serious multilinear relationship exists among independent variables, rendering estimation by ordinary regression unsuitable.

Table 6. Normalised coefficients of ridge regression.

\begin{tabular}{|c|c|c|c|c|c|c|c|c|c|}
\hline Region & $b_{1}$ & $b_{2}$ & $c_{1}$ & $c_{2}$ & $d_{1}$ & $d_{2}$ & $f$ & $R^{2}$ & $F$-test \\
\hline Guangdong & $0.16143^{* * *}$ & $0.09757^{*}$ & $0.20748^{* * *}$ & $0.11888^{*}$ & 0.09238 & $0.50094^{* * *}$ & 0.02030 & 0.99060 & $165.64895^{* * *}$ \\
\hline Liaoning & $0.30666^{*}$ & $0.31346^{* *}$ & $0.35983^{* * *}$ & -0.11593 & $0.29241^{*}$ & $0.49216^{* * *}$ & -0.09990 & 0.98299 & $45.00372^{* * *}$ \\
\hline Hubei & -0.04832 & 0.15547 & $0.74150^{* * *}$ & -0.07870 & $0.48750^{* *}$ & $0.737778^{* * *}$ & -0.18966 & 0.97936 & $36.88715^{* * *}$ \\
\hline Shaanxi & $0.21231^{* * *}$ & $0.14207^{* * *}$ & $0.25730^{* * *}$ & $0.15662^{* * *}$ & $0.28272^{* * *}$ & $0.33060^{* * *}$ & 0.00710 & 0.99763 & $330.33831^{* * *}$ \\
\hline Yunnan & $0.34992^{* * *}$ & $0.22110^{* * *}$ & $0.22337^{* * *}$ & $0.11883^{* * *}$ & $0.33863^{* * *}$ & $0.13662^{* * *}$ & 0.01029 & 0.99710 & $269.70432^{* * *}$ \\
\hline Hainan & $0.14121^{* * *}$ & $0.10659^{* * *}$ & $0.14832^{* * *}$ & $0.12276^{* * *}$ & $0.35608^{* * *}$ & $0.18388^{* * *}$ & -0.03364 & 0.99707 & $266.58306^{* * *}$ \\
\hline
\end{tabular}

Note: "Significant at $10 \%,{ }^{* *}$ significant at $5 \%,{ }^{* * *}$ significant at $1 \%$

Table 7. Coefficients of ridge regression.

\begin{tabular}{|c|c|c|c|c|c|c|c|c|c|}
\hline Region & $\ln a$ & $b_{1}$ & $b_{2}$ & $c_{1}$ & $c_{2}$ & $d_{1}$ & $d_{2}$ & $f$ & Max VIF \\
\hline Guangdong & 1.10097 & $0.44674^{* * *}$ & $0.41912^{*}$ & $0.24925^{* * *}$ & $0.06261^{*}$ & 0.38390 & $7.25828^{* * *}$ & 0.02979 & 6.2356 \\
\hline Liaoning & -30.33471 & $4.32459^{*}$ & $2.12308^{* *}$ & $0.31387^{* * *}$ & -0.04699 & $0.45373^{*}$ & $4.25649^{* * *}$ & -0.11105 & 7.08170 \\
\hline Hubei & 14.03738 & -1.15722 & 1.04889 & $0.80273^{* * *}$ & -0.05072 & $0.99501^{* *}$ & $7.89570^{* * *}$ & -0.22724 & 9.36500 \\
\hline Shaanxi & $-48.73395^{* * *}$ & $6.40511^{* * *}$ & $1.11372^{* * *}$ & $0.54391^{* * *}$ & $0.24414^{* * *}$ & $1.47648^{* * *}$ & $4.98453^{* * *}$ & 0.01458 & 3.73780 \\
\hline Yunnan & $-25.98218^{* * *}$ & $3.63340^{* * *}$ & $1.61443^{* * *}$ & $0.57117^{* * *}$ & $0.26027^{* * *}$ & $1.67635^{* * *}$ & $3.31967^{* * *}$ & 0.01843 & 2.33630 \\
\hline Hainan & $-9.69933^{* * *}$ & $1.90594^{* * *}$ & $1.17263^{* * *}$ & $0.50169^{* * *}$ & $0.25742^{* * *}$ & $1.61236^{* * *}$ & $4.82597^{* * *}$ & -0.13776 & 1.98270 \\
\hline
\end{tabular}

Note: ${ }^{*}$ Significant at $10 \%,{ }^{* *}$ significant at $5 \%,{ }^{* * *}$ significant at $1 \%$. 
To overcome multicollinearity, we introduced ridge regression to estimate Eq. (7). Ridge regression resolves multicollinearity among variables by adding a nonnegative factor $(\mathrm{K})$ to align the coefficient with the regression equation. After multiple simulations, we found that ridge regression tends to be stable when $\mathrm{K}$ is 0.03 for Guangdong, 0.02 for Liaoning and Hubei, 0.05 for Shaanxi, 0.07 for Yunnan, and 0.08 for Hainan. Coefficients of the model variables appear in Tables 6 and 7 .

Table 6 shows that independent variables exhibit goodness of fit at 0.01 confidence and are reliable for assessing the effect of economic factors on carbon emissions via ridge regression. Table 7 shows the maximum value of each variance inflation factor as below 10 and eliminates multicollinearity. The coefficient of independent variables in Table 7 shows that population most affects carbon emissions in Shaanxi (coefficient 6.41) and least affects emissions in Hubei although the effect is not significant. The explanation is that Hubei belongs to the central rural labour force, a large population in perennial eastward migration for work. This floating population does not increase the province's carbon emissions and might reduce them. Population has a larger influence in Liaoning, Yunnan, and Hainan. The impact of urbanisation on carbon emissions is significant except in Hubei, which has turned to clean energy (natural gas, water, and electricity), reducing dependence on coal. The greatest impact appears in Liaoning, where carbon emissions rise by $2.12 \%$ when urbanisation rises by $1 \%$. A greater impact also is evident in Yunnan (coefficient 1.61). Economically undeveloped Yunnan started at a low base of urbanisation, and rapid urbanisation accelerated carbon emissions. Urbanisation exerted a small influence on carbon emissions in Guangdong (coefficient 0.42). Urbanisation in Guangdong started from a higher base and growth was comparatively slow, rendering its effect on carbon emissions less prominent. Overall, urbanisation is the presiding influence on carbon emissions. Developing a low-carbon economy requires addressing carbon emissions arising from urbanisation.

Per capita wealth is significant at 0.01 . It exhibits its greatest impact on carbon emissions in Hubei, where per capita wealth rose by $1 \%$ and carbon emissions by $0.80 \%$. Hubei is the backbone of China's efforts to implement the rise of central force policy, and rapid increases in per capita wealth entail greater energy consumption. With an energy structure dominated by coal, that wealth means higher carbon emissions. The wealth effect on carbon emissions is also great in Yunnan, where a 1\% increase raises carbon emissions by $0.57 \%$. Yunnan is a tourist province developing a consumer economy. Rising wealth stimulates consumption, which promotes expanded production and therefore energy consumption and carbon emissions. Per capita wealth exerts a minimal effect on carbon emissions in Guangdong. It is an economically developed province with high per capita income and a population aware of environmental protection. Therefore, its wealth effect on carbon emissions is little.
Only Hubei and Liaoning exhibit a negative wealth effect as measured by the squared coefficient of wealth. The Environmental Kuznets curve is evident there but not in the other pilot provinces.

The coefficient of energy intensity is significant for all pilot provinces except Guangdong. It is largest for Yunnan, where a $1 \%$ increase in energy intensity raises carbon emissions by $1.68 \%$. Hainan ranks second at $1.61 \%$. The coefficient is only 0.45 in Liaoning. The effects of energy intensity are insignificant for Guangdong.

The impact of industrial structure on carbon emissions is significant at 0.01 , and coefficients for all provinces exceed 1. It affects carbon emissions significantly. Industrial structure exerts the greatest influence on carbon emissions in Hubei, where a $1 \%$ alteration in industrial structure alters carbon emissions by $7.90 \%$. Guangdong ranked second (coefficient 7.26), followed by Shaanxi (coefficient 4.98) and Hainan (coefficient 4.83). Industrial structure exerts the greatest effect on carbon emissions in all provinces, making it the critical factor in controlling carbon emissions.

a)

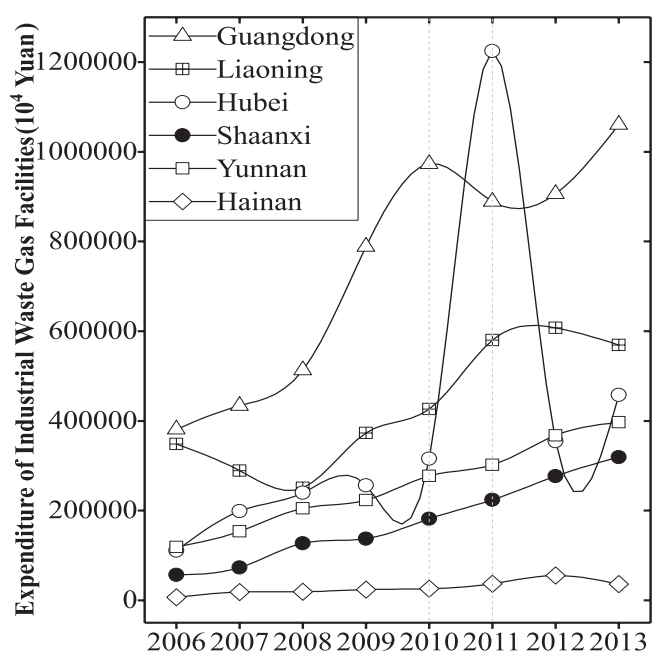

b)

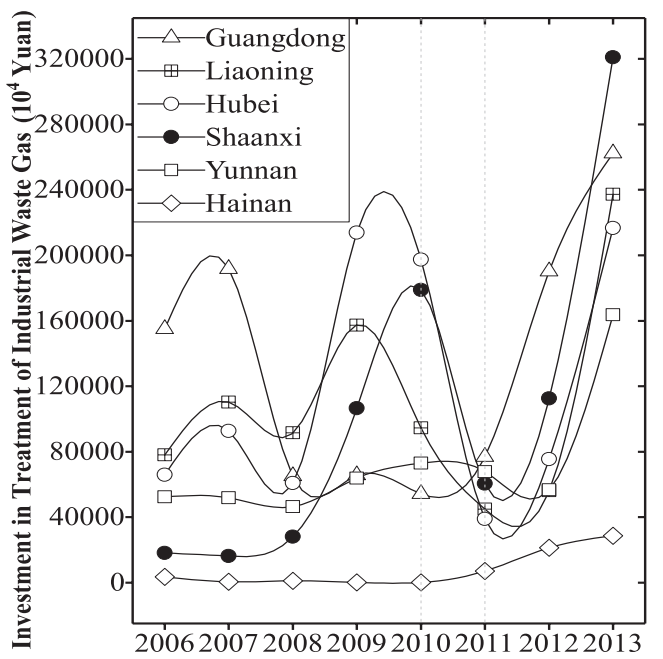

Fig. 3. Expenditures on industrial waste gas treatment facilities a) and investment in treatment of industrial waste gas b) in China's low-carbon pilot provinces. 


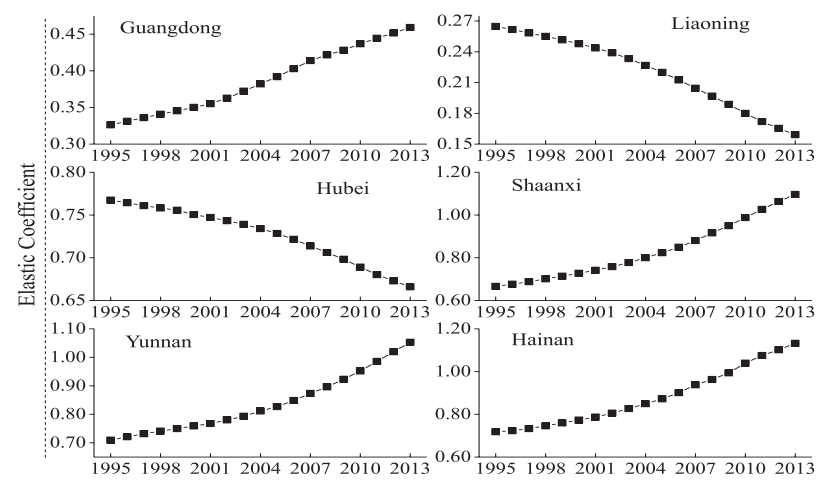

Fig. 4. Impact of per capita wealth on carbon emissions in lowcarbon pilot provinces.

The policy factor inhibits carbon emissions in Liaoning, Hubei, and Hainan, and is insignificant elsewhere. Environmental policy suffers a time lag before taking effect. China initiated its low-carbon pilot policy in 2010, and assessing its effectiveness requires a longer period of observation. However, we also must understand that provinces are motivated to participate in low-carbon pilot projects to obtain development opportunities. If local low-carbon investment and promotion impair economic growth, local leaders might shun the investment required by these initiatives.

Fig. 3 indicates expenditures on facilities to treat industrial waste gas and investment in those facilities following 2010, the year carbon pilots were initiated. Expenditures in Hubei, Liaoning, and Hainan rapidly increased after 2010. Expenditures did not rise significantly in Shaanxi and Yunnan and declined in Guangdong. These findings may explain why pilot policies have been inhibiting only in Hubei, Shaanxi, and Yunnan. Four provinces show downwardly trending investment in treatment of industrial waste gas in 2010 . Increases appear only in Hainan and Guangdong. In 2011, all pilot provinces began to increase investment. To some extent, the effectiveness of pilot policies is subject to the government's willingness to invest.

Following Eq. (8), we calculated how the coefficient of per capita wealth impacts carbon emissions. Results are in Fig. 4. Per capita wealth and carbon emissions correlate negatively only in Liaoning and Hubei, where data support the Environmental Kuznets Curve. In other provinces, per capita wealth and environmental pressure share a positive linear relationship. Coefficients of elasticity in Yunnan, Hainan, and Shaanxi exceed 1, indicating that environmental consequences are sensitive to increases in per capita wealth. Environmental pressures are difficult to relieve in a short time in these pilot provinces.

To further evaluate the robustness of regression results, we applied substituted variables in Eq. (7). We replaced carbon emissions with energy consumption and energy intensity with carbon intensity. Reusing ridge regression to estimate model (7), we obtained the results shown in Table 8 .

The model fit is good in Table 8 compared with Table 7. Symbols of variable coefficient do not change certainly, nor are there obvious changes in the significance of coefficients for each variable. The regression results are robust.

\section{Conclusions and Policy Implications}

Rapid economic development raises carbon emissions, and escalating carbon emissions have intensified pressures for environmental governance in China. The government's initiation of low-carbon pilot projects was an important initiative in reducing carbon emissions, but few scholars have evaluated its effectiveness. This study has addressed that deficiency in the literature by analysing the relationship between economic development and carbon emissions in China's low-carbon pilot provinces. Its empirical results present the following conclusions.

First, China's low-carbon pilot programme has yielded progress as evident by downtrends in carbon emissions and carbon emission intensity. Carbon emissions and economic development are related closely in the lowcarbon pilot provinces. Intensity of carbon emissions and economic development correlate negatively, indicating that the pilot programme has reduced carbon emission intensity. However, energy consumption is higher in provinces struggling for economic development, so it is imperative to transform development.

Table 8. Results of the robustness test.

\begin{tabular}{|c|c|c|c|c|c|c|c|c|c|}
\hline Region & $\ln a$ & $b_{1}$ & $b_{2}$ & $c_{1}$ & $c_{2}$ & $d_{1}$ & $d_{2}$ & $f$ & Max VIF \\
\hline Guangdong & 3.05952 & $0.36331^{* * *}$ & $0.48130^{*}$ & $0.28818^{* * *}$ & $0.10213^{*}$ & 0.20530 & $5.52294^{* * *}$ & 0.03086 & 5.51250 \\
\hline Liaoning & -10.57981 & $2.08337^{*}$ & $2.19797^{* *}$ & $0.33915^{* * *}$ & -0.04392 & $0.33112^{*}$ & $2.97340^{* * *}$ & -0.10254 & 8.70850 \\
\hline Hubei & 7.80357 & -0.32653 & 1.27205 & $0.75577^{* * *}$ & -0.05591 & $0.97247^{* *}$ & $6.46534^{* * *}$ & -0.25938 & 9.30120 \\
\hline Shaanxi & $-49.17929^{* * *}$ & $1.19413^{* * *}$ & $0.54753^{* * *}$ & $0.29577^{* * *}$ & $0.29577^{* * *}$ & $1.37831^{* * *}$ & $5.01431^{* * *}$ & 0.03553 & 3.74980 \\
\hline Yunnan & $-23.59802^{* * *}$ & $3.40976^{* * *}$ & $1.54053^{* * *}$ & $0.61636^{* * *}$ & $0.37505^{* * *}$ & $1.67187^{* * *}$ & $3.44904^{* * *}$ & 0.00040 & 2.33800 \\
\hline Hainan & $-10.1263^{* * *}$ & $2.03504^{* * *}$ & $1.01303^{* * *}$ & $0.59562^{* * *}$ & $0.35561^{* * *}$ & $1.98397^{* * *}$ & $5.12532^{* * *}$ & -0.01892 & 1.99400 \\
\hline
\end{tabular}

Note: ${ }^{*}$ significant at $10 \%,{ }^{* *}$ significant at $5 \%,{ }^{* * *}$ significant at $1 \%$ 
Second, economic development correlates positively with carbon emissions in low-carbon pilot provinces. Our decoupling analysis indicated that rapid economic growth increases carbon emissions. Empirical results established weak decoupling in developed provinces, but lessdeveloped provinces experienced an evolution from weak decoupling to expansionary negative decoupling to weak decoupling. Since China implemented its low-carbon pilot policy, carbon emissions and intensity have declined significantly, especially in developed provinces, indicating that economic development influences the control of carbon emissions. Industrialisation and urbanisation are important for less-developed provinces, suggesting that carbon emissions will continue to increase with economic growth. It is necessary to improve industrial energy efficiency and suppress excessive urbanisation expansion.

Third, industrial structure and population size significantly affect carbon emissions, and regional differences are evident. In Guangdong, industrial structure, population size, per capita wealth, and technological progress are the key to promoting reductions in carbon emissions. Population and industrial structure exert the greatest effects on carbon emissions in Liaoning. The squared coefficient of per capita wealth is negative, confirming the Environmental Kuznets Curve, yet the coefficient of energy intensity is positive, indicating an obvious effect of technological progress on carbon emissions. In Hubei, Shaanxi, Yunnan, and Hainan, industrial structure and population exert a greater impact on carbon emissions. For most pilot provinces, per capita wealth and carbon emissions display a linear relationship, indicating no evidence of the Environmental Kuznets Curve.

As the world's largest emitter of greenhouse gasses, China's carbon emissions and its contributing factors are of international concern. The relationship between carbon emissions and economic development in low-carbon pilot provinces opens a window to further observe China's carbon emissions reduction. Our results can inform China's future carbon emissions policy. China's provinces have developed unevenly and have large differences in carbon emissions. So long as economic development remains a priority, carbon emissions will rise. Nonetheless, our findings suggest that China's low-carbon pilot policy is effective in reducing carbon emissions and carbon intensity.

Our findings highlight that low-carbon initiatives should be based on the regions' actual conditions and that low-carbon strategies should be implemented gradually. We advocate the following policy framework.

First, we found that regional economic performance and development strategies relate closely to carbon emissions. Following the implementation of low-carbon pilot projects, carbon intensity declined significantly in economically developed Guangdong and the tourist provinces of Yunnan and Hainan. In general, the greater the economic development, the lower the carbon intensity. Therefore, low-carbon initiatives should continue to promote provincial economies. China's other tourist regions may learn from the experience of Yunnan and Hainan by developing green tourism, thereby reducing the proportion of heavy chemical industries in the national economy. Local governments should adhere to business services oriented, accelerating the transformation and upgrading of industrial structure, promoting clean production and green transportation and boosting lowcarbon development.

Second, population remains the central influence on China's carbon emissions. Notwithstanding slower population growth, a larger population base portends massive carbon emissions. Therefore, curbing population is important for reducing carbon emissions. Familyplanning policies have accelerated the greying of China's population and those policies will likely be liberalised. Our results suggest that a moderate family-planning policy is beneficial for reducing carbon emissions. Moreover, we note that China's population growth may be concentrated in rural areas after the family-planning policy is liberalised (most townsfolk are unwilling to bear more children because of the high cost of raising families). The rural populace is generally less educated and less aware of environmental protection; hence, governments need to increase investment in rural education to enhance villagers' environmental awareness.

Third, our results reveal that industrial structure significantly influences emissions in pilot provinces. Carbon mitigation requires adjusting the industrial structure. Given that carbon emissions arise mainly from industry, local governments need to phase down heavy chemical industries and improve the ratio of service businesses. All levels of governments should boost investment in science and technology to speed product innovation, abating industrial carbon emissions. Industries must reduce energy consumption and enhance energy efficiency in every way.

Fourth, emissions in Guangdong are mainly driven by the industrial structure and population. Therefore, lowcarbon initiatives should seek to adjust industrial structure by importing high-tech industries, reducing resourcedependent industries, reducing the proportion of heavy industries, and reversing the low proportion of services. Governments should moderate population growth and inflows, certify low-carbon products, and promote lowcarbon lifestyles.

Carbon emissions in Liaoning are mainly affected by the population, industrial structure, and urbanisation. As an old industrial base with a large population, it needs to restrain population growth, accelerate industrial upgrading, improve energy efficiency, and invest in technology to reduce energy consumed in the production of industrial products.

Low-carbon initiatives in Hubei should emphasise adjusting the industrial structure and improving energy efficiency. Industrial restructuring should focus on heavy chemical industries, using its mid-regional location to develop logistics, transportation, and e-commerce. Enterprises should take advantage of numerous research institutions to develop and enhance technologies to 
reduce energy consumption. Governments should support education to improve the population diathesis and enhance their environmental awareness.

Population and industrial structure govern carbon emissions in Shaanxi. Policymakers need to control population size and alter the province's coal-dominated energy structure. Shaanxi has abundant tourism resources. Local government should focus on tourism to drive the expansion of the service sector. Home to numerous scientific institutes, Shaanxi should build high-tech industrial parks, further improving energy efficiency.

Yunnan's needs are to control population growth, adjust its industrial structure, and improve education to strengthen the residents' low-carbon awareness. Yunnan should continue to expand tourism, focusing on the flower industry, health tourism, border trade, and other services.

Hainan needs to optimise its industrial structure and inhibit population growth. Local governments invest more in tourism, gradually raising the proportion of services in its industrial structure. Policymakers must consider population control, especially excessive population inflows, to depress carbon growth caused by a population explosion.

\section{References}

1. LI H., MU H., ZHANG M., GUI S. Analysis of regional difference on impact factors of China's energy - Related $\mathrm{CO}_{2}$ emissions, Energy, 39 (1), 319, 2012.

2. KAIKA D., ZERVAS E. The Environmental Kuznets Curve (EKC) theory - Part A: Concept, causes and the $\mathrm{CO}_{2}$ emissions case, Energy Policy, 62 (5), 1392, 2013.

3. HALICIOGLU F. An econometric study of $\mathrm{CO}_{2}$ emissions, energy consumption, income and foreign trade in Turkey, Energy Policy, 37 (3), 1156, 2009.

4. PULIAFITO S.E., PULIAFITO J.L., GRAND M.C. Modeling population dynamics and economic growth as competing species: An application to $\mathrm{CO}_{2}$ global emissions, Ecological Economics, 65 (3), 602, 2008.

5. AL-MULALI U., FEREIDOUNI H.G., LEE J.Y.M, SAB C.N.B.C. Exploring the relationship between urbanization, energy consumption, and $\mathrm{CO}_{2}$ emission in MENA countries, Renewable and Sustainable Energy Reviews, 23 (4), 107, 2013.

6. YAVUZ N.Ç. $\mathrm{CO}_{2}$ Emission, Energy Consumption, and Economic Growth for Turkey: Evidence from a Cointegration Test With a Structural Break, Energy Sources, Part B: Economics, Planning, and Policy, 9 (3), 229, 2013.

7. LAU L.-S., CHOONG C.-K., ENG Y.-K. Investigation of the environmental Kuznets curve for carbon emissions in Malaysia: Do foreign direct investment and trade matter?, Energy Policy, 68 (5), 490, 2014.

8. SHAHBAZ M., KHRAIEF N., UDDIN G.S., OZTURK I. Environmental Kuznets curve in an open economy: A bounds testing and causality analysis for Tunisia, Renewable and Sustainable Energy Reviews, 34 (3), 325, 2014.

9. GALEOTTI M., LANZA A., PAULI F. Reassessing the environmental Kuznets curve for $\mathrm{CO}_{2}$ emissions: a robustness exercise, Ecological Economics, 57 (1), 152, 2006.

10. YANG G., SUN T., WANG J., LI X. Modeling the nexus between carbon dioxide emissions and economic growth, Energy Policy, 86 (6), 104, 2015.
11. JAYANTHAKUMARAN K., VERMA R., LIU Y. CO emissions, energy consumption, trade and income: $\mathrm{A}$ comparative analysis of China and India, Energy Policy, $\mathbf{4 2}$ (1), 450, 2012.

12. FODHA M., ZAGHDOUD O. Economic growth and pollutant emissions in Tunisia: An empirical analysis of the environmental Kuznets curve, Energy Policy, 38 (2), 1150, 2010.

13. HAGHNEJAD A., DEHNAVI J. Energy consumption, economic growth, andpol-lution inselected OPEC countries: testing the environmental Kuznetscurve hypothesis, Journal of Academic Research in Economics, 4 (2), 149, 2012.

14. WANG S.S., ZHOU D.Q., ZHOU P., WANG Q.W. $\mathrm{CO}_{2}$ emissions, energy consumption and economic growth in China: A panel data analysis, Energy Policy, 39 (9), 4870, 2011.

15. AKBOSTANCI E., TÜRÜT-AŞIK S., TUNÇ G.İ. The relationship between income and environment in Turkey: Is there an environmental Kuznets curve?, Energy Policy, 37 (3), 861, 2009.

16. WU H., GU S., GUAN X., LU S. Analysis on Relationship between Carbon Emissions from Fossil Energy Consumption and Economic Growth in China, Journal of Natural Resources, 28 (3), 381, 2013.

17. DU L., WEI C., CAI S. Economic development and carbon dioxide emissions in China: Provincial panel data analysis, China Economic Review, 23 (2), 371, 2012.

18. FENG K., HUBACEK K., GUAN D. Lifestyles, technology and $\mathrm{CO}_{2}$ emissions in China: A regional comparative analysis, Ecological Economics, 69 (1), 145, 2009.

19. WANG Z., YIN F., ZHANG Y., ZHANG X. An empirical research on the influencing factors of regional $\mathrm{CO}_{2}$ emissions: Evidence from Beijing city, China, Applied Energy, 100 (4), 277, 2012.

20. WANG P., WU W., ZHU B., WEI Y. Examining the impact factors of energy-related $\mathrm{CO}_{2}$ emissions using the STIRPAT model in Guangdong Province, China, Applied Energy, 106 (11), 65, 2013.

21. ZHANG C., LIN Y. Panel estimation for urbanization, energy consumption and $\mathrm{CO}_{2}$ emissions: A regional analysis in China, Energy Policy, 49 (10), 488, 2012.

22. ACARAVCI A., OZTURK I. On the relationship between energy consumption, $\mathrm{CO}_{2}$ emissions and economic growth in Europe, Energy, 35 (12), 5412, 2010.

23. RAFINDADI A.A. Does the need for economic growth influence energy consumption and $\mathrm{CO}_{2}$ emissions in Nigeria? Evidence from the innovation accounting test, Renewable and Sustainable Energy Reviews, 62 (2), 1209, 2016.

24. SHAHBAZ M., LOGANATHAN N., MUZAFFAR A.T., AHMED K., ALI JABRAN M. How urbanization affects $\mathrm{CO}_{2}$ emissions in Malaysia? The application of STIRPAT model, Renewable and Sustainable Energy Reviews, 57 (7), 83, 2016.

25. ALKHATHLAN K., JAVID M. Energy consumption, carbon emissions and economic growth in Saudi Arabia: An aggregate and disaggregate analysis, Energy Policy, 62 (7), $1525,2013$.

26. REN S., YUAN B., MA X., CHEN X. The impact of international trade on China's industrial carbon emissions since its entry into WTO, Energy Policy, 69 (3), 624, 2014

27. TAJUDEEN I.A. Examining the role of energy efficiency and non-economic factors in energy demand and $\mathrm{CO}_{2}$ emissions in Nigeria: Policy implications, Energy Policy, 86 (6), 338, 2015. 
28. WANG S.-H., SONG M.-L. Review of hidden carbon emissions, trade, and labor income share in China, 2001-2011, Energy Policy, 74 (4), 395, 2014.

29. WANG S., FANG C., GUAN X., PANG B., MA H. Urbanisation, energy consumption, and carbon dioxide emissions in China: A panel data analysis of China's provinces, Applied Energy, 136 (6), 738, 2014.

30. ZHANG J. Carbon emission, energy consumption and intermediate goods trade: A regional study of East Asia, Energy Policy, 86 (6), 118, 2015.

31. FAN J.-L., LIAO H., LIANG Q.-M., TATANO H., LIU C.-F., WEI Y.-M. Residential carbon emission evolutions in urban-rural divided China: An end-use and behavior analysis, Applied Energy, 101 (1), 323, 2013.

32. GU Z.H., SUN Q., WENNERSTEN R. Impact of urban residences on energy consumption and carbon emissions: An investigation in Nanjing, China, Sustainable Cities and Society, 7 (2), 52, 2013.

33. REN S., HU Z. Effects of decoupling of carbon dioxide emission by Chinese nonferrous metals industry, Energy Policy, 43 (2), 407, 2012.

34. REN S., FU X., CHEN X. Regional variation of energyrelated industrial $\mathrm{CO}_{2}$ emissions mitigation in China, China Economic Review, 23 (4), 1134, 2012.

35. LIANG Q.-M., FAN Y., WEI Y.-M. Multi-regional inputoutput model for regional energy requirements and $\mathrm{CO}_{2}$ emissions in China, Energy Policy, 35 (3), 1685, 2007.

36. JIANG K., DU X. Energy demand and emissions in 2030 in China: scenarios and policy options, Environmental Economics and Policy Studies, 7 (3), 233, 2006.

37. GOLLEY J., MENG X. Income inequality and carbon dioxide emissions: The case of Chinese urban households, Energy Economics, 34 (6), 1864, 2012.

38. DONGLAN Z., DEQUN Z., PENG Z. Driving forces of residential $\mathrm{CO}_{2}$ emissions in urban and rural China: An index decomposition analysis, Energy Policy, 38 (7), 3377, 2010.

39. POUMANYVONG P., KANEKO S. Does urbanization lead to less energy use and lower $\mathrm{CO}_{2}$ emissions? A cross-country analysis, Ecological Economics, 70 (2), 434, 2010.

40. ZHAO X., SUN B. The influence of Chinese environmental regulation on corporation innovation and competitiveness, Journal of Cleaner Production, 112 (4), 1528, 2016.

41. HUANG Q., GAO M. Study on the Energy-Saving and Emission-Reducing Effect of Environmental Regulation: Based on the Empirical Analysis of the Panel Quantile, Science of Science and Management of S\&T, 38 (1), 30, 2017.

42. ZHANG H., WEI X. Green paradox or forced emissionreduction: dual effect of environmental regulation on carbon emissions, China Population,Resources and Environment, 24 (9), 21, 2014.

43. HUANG Q., GAO M. A research on the energy conservation and emission reduction effect of China's environmental regulation tools, Science Research Management, 37 (6), 19, 2016.

44. ZHANG X.-F., HAN X., WU J.-J. Relationship between Environmental Regulation and Carbon Emission: Reverse Effect or Regressive Effect - Based on Provincial Panel Data from 2000 to 2010, Soft Science, 28 (4), 136, 2014.

45. SIMÕES P., MARQUES R.C. Influence of regulation on the productivity of waste utilities. What can we learn with the Portuguese experience?, Waste Management, 32 (6), 1266, 2012.

46. SIMÕES P., DE WITTE K., MARQUES R.C. Regulatory structures and operational environment in the Portuguese waste sector, Waste Management, 30 (6), 1130, 2010.

47. SIMÕES P., MARQUES R.C. How does the operational environment affect utility performance? A parametric study on the waste sector, Resources, Conservation and Recycling, 55 (7), 695, 2011.

48. EHRLICH P.R., HOLDREN J.P. Impact of Population Growth, Science, 171 (3977), 1212, 1971.

49. FAN Y., LIU L.C., WU G., WEI Y.M. Analyzing impact factors of $\mathrm{CO}_{2}$ emissions using the STIRPAT model, Environmental Impact Assessment Review, 26 (4), 377, 2006.

50. YORK R., ROSA E.A., DIETZ T. STIRPAT, IPAT and ImPACT: analytic tools for unpacking the driving forces of environmental impacts, Ecological Economics, 46 (3), 351, 2003. 